\title{
USING ROLE PLAY EXERCISES TO ENHANCE COMMUNICATION COMPETENCE AND PERSUASIVE COMMUNICATION SKILLS IN ENTREPRENEURSHIP PROGRAMS
}

\author{
George A. Kirk, Southern University, george_kirk@subr.edu
}

\begin{abstract}
Student interest in entrepreneurship as a career alternative has grown in recent years. In response, a growing number of colleges and universities are offering entrepreneurial curriculum. Traditionally university based entrepreneurial training has focused primarily on business based technical skills, i.e., accounting, management, marketing and finance. Persuasive communication and communication competence are vital skills that are often overlooked in entrepreneurship programs. This paper provides a brief overview of the skills required for communication competence and proposes a method for enhancing persuasive communication skills and communication competence in budding entrepreneurs - role play exercises. Role play exercises allow students to develop, enhance and practice their communication skills as well as building communication confidence. Role play exercises can be added to existing classes or administered through extra-curricular activities to avoid having to add an additional course to the curriculum. Role play exercises can also provide a mechanism for creating awareness of the entrepreneurship program both on campus and off campus.
\end{abstract}

Keywords: Entrepreneurship Education, Role Play Exercises, Verbal Communication Skills, Communication Competence, Persuasive Communication

\section{INTRODUCTION}

Entrepreneurship is becoming a popular career option for many recent college graduates. Many colleges and universities have responded to this demand by offering entrepreneurship programs-majors, minors and concentrations. Typically, such programs are offered by the college of business. The interest in entrepreneurship education is not limited to the college of business. Numerous IT authors, noting the growing number of IT based entrepreneurial ventures, have suggested that entrepreneurship content be incorporated into IT and IS curriculum (Davidson, White and Taylor, 2012; Chen, 2013; Jones and Liu, 2017). Quite often students majoring in IT comprise the target market for entrepreneurship minors. Given that entrepreneurship education is a growing field, serving a wide range of students from different backgrounds across different majors, a key question regarding entrepreneurship education is what skills and abilities should be included in the content of entrepreneurial curriculum?

This paper will provide a brief overview of the skill sets typically covered in entrepreneurial education, discuss the importance of infusing persuasive communication skills into entrepreneurial programs as well as offering a method for developing persuasive communication skills to students — role play exercises.

\section{ENTREPRENEURIAL SKILLS}

Entrepreneurial education has grown dramatically in the last few years (Davidson, White and Taylor, 2012; De Grez and Van Lindt, 2013; Jones and Liu, 2017). Entrepreneurship requires numerous skills and many colleges and universities offer programs in entrepreneurship to develop and enhance these skills in potential entrepreneurs. Elmuti, Khoury and Omran (2012) suggest that the skills required of entrepreneurs fall into three categories - technical skills which includes verbal and written communication, business management skills which includes management, marketing, accounting and finance and personal entrepreneurial skills including risk taking, innovation and persistence. Typically, entrepreneurship programs focus on business management skills and personal entrepreneurial skills. In many cases, the culmination of the such programs is a written business plan. Business plans usually focus on technical elements such as business feasibility, cash flow and the like. 
While constructing a business plan is a vital part of the entrepreneurship/small business establishment process, it is not the only hurdle that potential entrepreneurs face. Frequently, potential entrepreneurs are required to "pitch" their business/product ideas to potential investors to gain funding. Lucas, Kerrick, Haugen and Crider (2016), report that often potential entrepreneurs have difficulty translating their passion for the business or product idea into their presentation often resulting in missed opportunities for funding for these potential entrepreneurs. It is also important that potential entrepreneurs write their business plan in a way such that the plan is persuasive and communicates their passion as well as their vision for the venture. Many potential entrepreneurs may not know how to prepare their business plan and presentation in a way such as to persuade potential stakeholders to invest in their business idea. While business idea quality, feasibility and cash flow are major factors in the successful presentation of a business plan or pitch, presentational factors also play a major role in the outcome decision (Clark, 2008; Chen, Yao, and Kotha, 2009). Business plans - both presented verbally and in written format must be persuasive.

The need for persuasive communication skills and communication competence extends beyond the "pitches" usually required to secure investors or initial funding. If a venture is funded and launched, the entrepreneur, now business operator must be able to attract stakeholders to support the business (Ulvenblad, 2008). Often, entrepreneurs must communicate with and motivate employees and communicate and interact with potential vendors for their product or service. Business owner/operators must also be able to communicate and interact with customers in a variety of settings including promoting the business among the customers and dealing with both satisfied and unsatisfied customers. Business owners must also be able to interact with and negotiate with suppliers and supply chain intermediaries. In addition, business owners may have to deal with local, state and federal governmental entities. In short, an entrepreneur turned business owner/operator faces ample situations where communication competence and persuasive communication skills are required. Arora and Sharma (2017) suggest that persuasive communication on the part of the entrepreneur/leader is instrumental the success of an entrepreneurial venture. Arora and Sharma (2017) argue that persuasive communication and empathy are superior to coercive communication methods in securing cooperation from stakeholders. Despite the importance of persuasive verbal communication skills and communication competence, frequently these skills are not addressed in entrepreneurial curriculum. The next section of this paper provides a brief review of critical communication skills that comprise communication competence.

\section{COMMUNICATION SKILLS}

A wide range of communication skills necessary for business success have been examined in the literature. These skills include, 1) listening, 2) empathy, 3) altercentrism, 4) attentiveness, 5) articulation, 6) interaction management and 7) adaptability (Payne, 2005). Several authors have suggested communication skills by themselves are not adequate, many authors argue that what individuals really need in a business setting is communication competence (Spitzberg and Cupach, 1984, 1989; Payne, 2005; Madlock, 2008). In addition to communication skills, communication competence requires knowledge of communication, motivation to communicate, as well as being able to manage contextual factors inherent in the communication process (Spitzberg and Cupach, 1984; Payne, 2005). The next section of this paper will briefly discuss communication skills.

\section{Listening}

Listening is a multidimensional skill comprised of sensing, processing and responding (Ramsey and Sohi, 1997; Comer and Drollinger, 1999; Drollinger, Comer, and Warrington, 2006). There are different levels of listening, ranging from marginal, evaluative, and active listening (Alessandra, Wexler and Barrara 1987). Comer and Drollinger (1999) proposed active empathic listening (AEL) which they defined "as a process whereby the listener: receives verbal and non-verbal messages, processes them cognitively, responds to them verbally and non-verbally (p. 18)" as a preferred method of listening. Listening is not confined to audio information, perceiving non-verbal communication is also vitally important - experts estimate that majority of what people communicate in a conversation is non-verbal in nature (Fromkin and Rodman, 1983). It is important that communicators be able to read and interpret body language. In a professional sales context, Byron, Terranova and Nowicki (2007) found a positive relationship between the ability of sales representatives to read client facial emotional expressions and performance. 


\section{Empathy, Altercentrism and Attentiveness}

Perceived concern for others is also a vital communication skill. Empathy has been defined as the ability to "spontaneously adopt the psychological point of view of others" (Davis, 1983, p. 113-114). Empathy helps individuals adapt communications as well as formulate communication. Spiro and Weitz defined empathy as "the reaction of individuals to the observed experiences of other individuals" $(1990$, p. 63). Often, individuals display empathy by demonstrating attentiveness - responding another person's comments either verbally or non-verbally (Payne 2005). Giacobbe, Jackson, Crosby, and Bridges adapted the Spiro and Weitz definition and incorporated elements from the Davis definition to define empathy as "the ability of salespeople to spontaneously adopt the perspective of their customers through intellectual apprehension of their mental state or condition, thereby generating a genuine feeling of concern toward the customer" (2006, p. 121). Concern for the wellbeing of another individual is referred to in the literature as altercentrism. Payne (2005) discussed the need for altercentrism in an organizational context.

\section{Interaction Management, Adaptability and Articulation}

Interaction management refers to the knowledge of when to and just as importantly, when not to communicate. Payne (2005) argues that it is impossible to separate interaction management and adaptability. The importance of adaptive communication has long been a topic in the sales literature. Adaptive selling refers to the ability to modify a sales presentation during the sales presentations or in subsequent presentations based on perceived information about the selling situation (Weitz, Sujan, and Sujan 1986). It is important to note adaptive communication does not limit perceived information to verbal information. Byron, Terranova and Nowicki (2007) suggest that although extant adaptive selling research has focused on verbal information, non-verbal information such as the emotional expressions in a person's face are also important and may require that the salesperson adapt the presentation to suit the needs of the person or persons being presented to.

Articulation is far more than just the words that one uses and the style in which one speaks. Business has a unique language. Expressions like "bottom line" or "in the red" have meaning that is understood by most if not all business people. Discussing business situations with lay people however often requires using less jargon and providing greater explanatory detail to convey meaning. On a broader note, successful business communication must also take into account contextual factors. Contextual factors include, patterns of interaction, norms and rules, type of relationship between the communicators, setting, and activities, to name but a few. Contextual factors greatly alter the communication process. In professional sales, students are taught how to incorporate contextual factors into conversation - build rapport, personalize sales encounters and enhance the value of communication. Likewise, potential entrepreneurs should also personalize their communications with stakeholders to ensure that critical concerns of the stakeholder are addressed.

\section{COMMUNICTION COMPETENCE}

Teaching communication skills is a necessary first step in developing communication competence among our students. However, as illustrated by Spitzberg (1990), communication skills by themselves do not make one competent in communication. In addition to communication skills, communication competence requires both communication knowledge and communication motivation-i.e., willingness to engage in communication.

\section{Communication Knowledge}

Communication knowledge represents the cognitive aspect of communication competence and refers to the ability of the communicator to know what to do or say during a communication encounter (Spitzberg, 1990; Duran and Spitzberg, 1995). To a large extent, it can be argued that communication knowledge can be increased as a result of experience and feedback from previous communication experiences. In sales education, role play exercises provide participants with the opportunity to practice different approaches, techniques and behaviors. This coupled with feedback from the instructor helps students to refine their communication abilities. Role play exercises need not be limited to selling situations. The range and scope of common business situations that individuals encounter provides fertile ground for a large number of role play exercises, including, but not limited to: presenting a business plan, interacting with customers/clients, interacting with employees, motivating employees, negotiating with vendors, 
suppliers and others. An important aspect of role play exercises is that students' can develop confidence. When they are faced with actual situations have experience to draw from, which may increase communication motivation.

\section{Communication Motivation}

Communication motivation refers to one's willingness to engage in communication. Some people, by their nature, are more willing than others to engage in communication. In the literature, many authors have examined communication apprehension. Some authors have even suggested that attempts to increase communication skills may in fact cause more harm than good due to communication apprehension. Gardner, Milne, Stringer and Whiting (2005) found that communication apprehension declined as students matriculated through accounting programs. This could be due to students having greater opportunity to practice/apply communication skills. Interestingly, Elias (1999) found that non-traditional accounting students (i.e., older students with previous work experience) displayed lower levels of both written and oral communication apprehension. It appears that practice and familiarity with oral communication reduces communication apprehension. The basic premise of the public speaking courses as well as programs like Dale Carnegie and Toastmasters is that exposure to and practice of public speaking reduces anxiety and apprehension. Unfortunately, students are not usually given a structured environment to practice and receive feedback on their interpersonal communication skills.

Communication competence and persuasive communication skills are vital to the budding entrepreneur and could mean the difference between successfully securing funding or not. The next section of this paper introduces role play exercises as a tool to enhance student communication skills.

\section{ROLE PLAY EXERCISES}

Role play exercises are commonly used in professional sales courses. Role play exercises provide students with the opportunity to practice a host of communication skills including listening, questioning, negotiating, teamwork as well as adaptive communication. De Grez and Van Lindt (2013) suggest that learning by doing plays an important role in in entrepreneurial education by enhancing student self-efficacy. Role play exercises provide an excellent opportunity for students to learn by doing. Role play exercises are commonly used in professional sales courses to provide students with the opportunity to practice specific communication/persuasive skills as well as develop self-confidence. Although role play exercises are often thought of as a tool used in sales education, the value of role play exercises is not limited to sales education (Pettenger, West and Young, 2014). In an entrepreneurial context, role play exercises provide a means for students to practice and refine their business plans, their communication skills and their selfconfidence. A wide variety of common reoccurring business situations can be modeled into role play exercises. Moreover, contextual factors can be incorporated and manipulated to further develop/enhance skills. Role play exercises also provide students with the opportunity to compete and prove their skills. Currently, there are several national and regional role play competitions held each year. There are also numerous entrepreneurial pitch competitions. Pitch and role play competitions also provide an opportunity for schools to promote their entrepreneurial program to create awareness of the program both on campus and in the business community as well as presenting an opportunity to gain support for the program from the business community.

Role play exercises are interactive and require the use of information contained or uncovered in the role play. It is very important that a potential entrepreneur be able to adapt, in real time, their presentation or pitch based on the reactions from the stakeholder. For example, if the potential investor is asking questions about cash flow, this may indicate that they are not yet sold on the profit potential of the venture which may result in the potential investor rejecting the idea. Likewise, it is important that entrepreneurs be able to recognize when a potential stakeholder has verbally or non-verbally shown interest or disinterest in an aspect of the business plan or presentation. Role play exercises offer a valuable training/preparation tool for entrepreneurship programs aimed both at business majors and non-business majors. Potential entrepreneurs need also be aware of contextual factors when making funding presentations - the funding history of the potential investor, key issues that the investor may be concerned with to name but a few.

Frequently role play exercises are video recorded providing the opportunity for entrepreneurial students to review their performance and improve their skills. Much of the value from role play exercises occurs when students see themselves in action and are debriefed by both the professor and the person that they presented to. The people that 
the entrepreneurial students are presenting to can offer feedback about what parts of the presentation or pitch went well and what parts of the presentation did not go well and make suggestions on how to improve the presentation or pitch. Role play exercises can also be used to help students learn to reinforce their presentations with elements of their own body language as well as help students to eliminate negative aspects of their own body language. Finally, role play exercises can help students become more comfortable in communication encounters.

In sales education, often consultative sales methods are taught — the sales representative works to find a solution that is beneficial for the buyer as well as the seller. In a new venture pitch, an entrepreneur must demonstrate concern for the potential investor as well as communicate the benefits for the investor. In fact, the entire business plan must address the viability as well as the potential for return to have any hope of securing investors. Potential entrepreneurs must also be able to convey their passion and vision for the business idea in hopes that potential stakeholders will share that passion and vision.

The interactive nature of role play exercises is well suited for students to develop and learn how to deploy empathy, altercentrism as well as attentiveness skills. Role play exercises also teach students the value of asking questions and then incorporating acquired information into the communication encounter in real time. Role play exercises offer the student the opportunity to improve listening skills as well as the opportunity to learn how to interpret body language. When debriefing is used, the presenter can discuss the encounter with the receiver of the presentation and learn how to improve future presentations. In the presentation of a business plan or a pitch, it is vital that the entrepreneur be able to pick up on and interpret all the information provided by the questioner-both verbal and non-verbal to frame their answers to adequately address the concerns that the stakeholder has.

Role play exercises are not limited to practicing and refining funding pitches. Role play exercises provide a means to practice communicating and motivating employees, negotiations with venders, suppliers, business partners as well as offering the opportunity to practice how to deal with unsatisfied clients and customers. Basically, many different potential communication encounters can be practiced using role play exercises. Table 1 displays the range of communication skills that can be enhanced using role play exercises.

Table 1. Skills that can be addressed in role play exercises

\begin{tabular}{|ll|}
\hline Communication Skill & Role play \\
\hline Listening & $\mathrm{X}$ \\
Empathy & $\mathrm{X}$ \\
Altercentrism & $\mathrm{X}$ \\
Attentiveness & $\mathrm{X}$ \\
Articulation & $\mathrm{X}$ \\
Interaction Management & $\mathrm{X}$ \\
Adaptability & $\mathrm{X}$ \\
Communication Knowledge & $\mathrm{X}$ \\
Communication Motivation & $\mathrm{X}$ \\
Body Language & $\mathrm{X}$ \\
\hline Business Situation & \\
Business Encounter & $\mathrm{X}$ \\
Funding Pitch & $\mathrm{X}$ \\
Selling a Client & $\mathrm{X}$ \\
Dealing with an Unsatisfied Client/Customer & $\mathrm{X}$ \\
Negotiation & $\mathrm{X}$ \\
Securing Business Partners & $\mathrm{X}$ \\
Securing Distribution & $\mathrm{X}$ \\
\hline
\end{tabular}




\section{ROLE PLAY ADMINISTRATION}

Traditionally, the roles in a role play exercise are seller and buyer. This this case, the entrepreneur takes on the role of the seller and the potential stakeholder takes on the role of the buyer. The type of stakeholder can vary from potential investor, business partner, supplier, employee, etc. Role play exercises will usually be conducted between two students, one taking on the role of the entrepreneur and the other taking on the role of the stakeholder. Role play exercises are usually timed and typically last for fifteen to twenty minutes. Some role plays may require that a student present to a panel of decision makers. Although it is common for students to play the role of the stakeholder or decision maker, in the case of the business pitch, business practitioners or actual investors and or bankers can be used to add realism as well as expertise. In addition to the professor, judges can also be used to evaluate role play exercises. For assessment purposes, it is often useful to assemble a panel of judges or observers to evaluate verbal communication exercises.

Each participant in a role play exercise is given a unique briefing sheet which contains key information about the situation, the setting for the communication, the issue involved and specific concerns that the person in their role may have. The entrepreneur will make use of their business plan along with the briefing sheet. Table 2 presents a profile that would be given to a potential entrepreneur. As shown, the profile contains a brief description of the person or organization that they will be "selling" to which should include a description of the investor's preferences, concerns and a brief list of elements common to business plans that they have invested in. This allows contextual factors to be incorporated as well as addresses critical thinking and problem-solving skills. Entrepreneurs are encouraged to provide any supporting material that they believe with strengthen their presentation. The investors will also be given a set of instructions as well as copies of supporting material provided by the entrepreneur, including if applicable, a brief business plan. Table 3 presents an example of a briefing sheet for a potential investor. Usually, these instructions include special concerns that the buyer or investor has which the seller or in this case the entrepreneur must uncover and address to successfully close the sale. Given that on many occasions students may be playing the role of the buyer it is useful to provide a list questions for them to ask as well as provide the individuals playing the buyer with verbal instructions. To make the role play exercise more realistic, actual bankers and investors may be invited to play the role of the buyer. To maximize the value of the role play exercises, rich contextual scenarios should be used. Depending on the situation, potential entrepreneurs may be presenting to one person or to a group of people. Also, the participants should be required to debrief each other as well as share their individual briefing scenarios. Each of individual role plays will focus on a specific skill. Thus, one issue may form the basis for several subsequent ongoing role plays.

Table 2. Investor Profile: To be provided to students

Maximize Investments is looking to provide start-up capital for new tech-based ventures. Over the course of the company's history, the firm has provided over $\$ 100$ million dollars to various firms. The firm enjoys a stellar reputation in the business community as a fair investor with reasonable terms. Your analysis of the last five firms that secured firms that secured funding from Maximize indicates the following:

Risk Tolerance: Moderate

Key areas of concern

Business feasibility

Cash flow

Profit potential

Pay-back period

Competitive advantage

Ability to service the debt 
Table 3. Investor Instructions: Not available to students until the debriefing

The firm is only interested in investing in business plans that have a high degree of feasibility. Factors include:
Competition-who are the current and potential competitors for the proposed venture?
Revenue potential—what are the revenue projections
Profit potential—what are the profit projections? What is the estimated time to profitability?
Ability to service the debt—will the firm be able to repay the debt?
Payback period-What is the payback period?
In addition to the business factors, you are also concerned with:
Does the entrepreneur have confidence in his or her idea?
Does the entrepreneur have passion for their idea/plan?
How well does the entrepreneur answer questions?

Generally, role plays are evaluated based on evidence of key persuasive communication elements such as eye contact, use of supporting materials, confidence, how well the entrepreneur addresses the concerns of the stakeholder, to name but a few evaluative criteria.

Upon completion of the role play exercise, the student participant should be debriefed by the professor and the judge(s) and the person playing the investor or stakeholder in the role play. Debriefing is a critical part of the success of a role play exercise because the potential entrepreneur benefits from the feedback received from the investor as well as the judge. If possible, role play exercises should be video recorded so that potential entrepreneurs can be given feedback on their body language and just as importantly, the body language of the investor.

Role play exercises can be integrated into an existing class or classes eliminating the need to create an additional class or if a minor, eliminate an existing class. Likely candidate classes to add role play exercises to include the applied marketing course and the business plan course based on the scope and purpose of these courses. For those on tighter course availability, role play exercises can be conducted as extra- curricular activities through student organizations or as an internal competition. Also, to generate awareness of the entrepreneurship program schools can hold oncampus competitions as well as sending student teams to local, regional or national competitions.

\section{CONCLUSION}

Communication competence and persuasive communication skills are vital in business and in entrepreneurship. Often however, entrepreneurial programs focus on technical and personal entrepreneurial aspects of entrepreneurship and may not provide students training nor a vehicle to enhance and practice their communication skills. Role play exercises offer an effective means for students to develop and enhance their communication competence and their persuasive communication skills as well as prepare for common communication encounters that they will likely face. The ability to practice and review realistic communication encounters adds value to both the students and to the entrepreneurial program. Role play exercises can be incorporated into existing classes or as an extra-curricular activity without having to add an additional course to the slate of classes that comprise the entrepreneurship program. As side benefit, entrepreneurial role play exercises can also provide a means to create awareness and promote the entrepreneurship program.

\section{REFERENCES}

Alessandra, A. J., Wexler, P., \& Barrera, R. (1987). Non-manipulative selling, Reston, VA: Reston Publishing Company.

Arora, M., \& Sharma, R. (2017). Decoding diverse dimensions of entrepreneurial leadership with special emphasis on persuasive communication. Management Dynamics, 17(1), 70-77. 
Byron, K., Terranova, S., \& Nowicki, S., Jr. (2007). Nonverbal emotion recognition and salespersons: Linking ability to perceived and actual success. Journal of Applied Social Psychology, 37(11), 2600-2619.

Chen, L. (2013). IT entrepreneurial intention among College Students: An Empirical Study. Journal of Information Systems Education, 24(3), 233-243.

Chen, X.-P., Yao, X. \& Kotha, S. (2009). Entrepreneur passion and preparedness in business plan presentations: A persuasion analysis of venture capitalists' funding decisions. Academy of Management Journal, 52(1), 199214.

Clark, C. (2008). The impact of entrepreneurs' oral 'pitch' presentation skills on business angels' initial screening investment decisions. Venture Capital, 10(3), 257-279.

Comer, L. B., \& Drollinger, T. (1999). Active empathetic listening and selling success: A conceptual framework. Journal of Personal Selling \& Sales Management, 19(Winter), 15-29.

Davis, M. H. (1983). Measuring individual differences in empathy: Evidence for a multidimensional approach. Journal of Personality and Social Psychology, 44, 113-126.

Davidson, B., White, B. Jo, \& Taylor, M. (2012). The Rise of IT for entrepreneurs and the increasing focus for IT professionals. Issues in Information Systems, 13(2), 104-111.

De Grez, L., \& Van Lindt, D. (2013). Students' gains in entrepreneurial self-efficacy: A comparison of 'LearningBy-Doing' versus lecture-based courses. Proceedings of the European Conference on Innovation \& Entrepreneurship, 198-203.

Drollinger, T, Comer, L. B. \& Warrington, P. T. (2006). Development and validation of the active empathetic listening scale. Psychology \& Marketing, 23(February), 161-180.

Duran, R. L., \& Spitzberg, B. H. (1995). Toward the development and validation of a measure of cognitive communication competence. Communication Quarterly, 43(3), 259-275.

Elias, R. Z. (1999). An examination of nontraditional accounting students' communication apprehension and ambiguity tolerance. Journal of Education for Business, 75(1), 38-41.

Elmuti, D., Khoury, G., \& Omran, O. (2012). Does entrepreneurship education have a role in developing entrepreneurship skills in venture effectiveness? Journal of Entrepreneurship Education, 15, 83-98.

Fromkin, V. \& Rodman, R. (1983). An introduction to language. Harcourt College Publishers.

Gardner, C. T., Milne, M. J., Stringer, C. P. \& Whiting, R. H. (2005). Oral and written communication apprehension in accounting students: Curriculum impacts and impacts on academic performance. Accounting Education: An International Journal, 14(3), 313-336.

Giacobbe, R. W., Jackson Jr. D. W., Crosby, L. A. \& Bridges, C. M. (2006). A contingency approach to adaptive selling behavior and sales performance: Selling situations and salesperson characteristics. Journal of Personal Selling \& Sales Management, 26(Spring), 115-142.

Jones, Ch. G., \& Liu, D. (2017). Approaches to incorporating IT entrepreneurship into the information systems curriculum. Journal of Information Systems Education, 28(1), 43-57.

Lucas, K., Kerrick, S., Haugen, J., \& Crider, C. (2016). Communicating entrepreneurial passion: Personal passion vs. perceived passion in venture pitches. IEEE Transactions on Professional Communication, 59(4), 363378. 
Madlock, P. E. (2008). The link between leadership style, communicator competence, and employee satisfaction. Journal of Business Communication, 45(1), 61-78.

Payne, Holly (2005). Reconceptualizing social skills in organizations: Exploring the relationship between communication competence, job performance, and supervisory roles. Journal of Leadership \& Organizational Studies, 11(2), 63-77.

Pettenger, M., West, D. \& Young, N. (2014). Assessing the impact of role play simulations on learning in Canadian and US Classrooms. International Studies Perspectives, 15(4), 491-508.

Ramsey, R. P., \& Sohi, R. S. (1997). Listening to your customers: The impact of perceived salesperson listening behavior on relationship outcomes. Journal of the Academy of Marketing Sciences, 25, 127-137.

Spiro, R. L., \& Weitz, B. A. (1990). Adaptive selling: Conceptualization, measurement, and nomological validity, Journal of Marketing Research, 27(February), 61-69.

Spitzberg, B. H. \& Cupach, W. R. (1984). Interpersonal communication competence. Beverly Hills: Sage.

Spitzberg, B. H. \& Cupach, W. R. (1989). Handbook of interpersonal competence research. New York: SpringerVerlag.

Spitzberg, B. H. (1990). The construct validity of trait-based measures of interpersonal competence, Communication Research Reports, 7, 107-115.

Ulvenblad, P. (2008). The challenge of communication (ChoC): Communicative skills in the start-up phase of a business," Small Enterprise Research, 16(1) 2-15.

Weitz, B. A, Sujan, H. \& Sujan, M. (1986). Knowledge, motivation, and adaptive behavior: A framework for improving selling effectiveness. Journal of Marketing, 50 (October), 174-191. 